\title{
THE MOST COMMON 5 PEDIATRIC ORAL LESIONS IN MIDDLE NILE DELTA, EGYPT
}

\author{
Talat M. Beltagy", Enas A. El-Gendy ${ }^{* *}$, Emad F. Essa ${ }^{* * *}$ and Ibrahim A. Kabbash ${ }^{* * * *}$
}

\begin{abstract}
Background: The prevalence studies on common pediatric oral lesions (POLs) are still rare compared with those on dental caries and periodontal diseases. POLs vary among different geographic regions, age, racial and lifestyle of each population. The purpose of this study was to determine the most common 5 POLs referred to 5 different dental and medical branches in Middle Nile Delta, Egypt.

Materials and methods: A qualitative study design was used depending on expert opinions on oral lesions in children (aged 0-14 years). A total of 1164 dental and medical staff members, dentists and physicians at the hospitals of Universities and Ministry of Health, and Specialized Medical Centers \& hospitals in the Middle Nile Delta region were included. The target population of the study was experts in 5 branches: Pedodontics, Oral Medicine and Periodontology, Oral and Maxillofacial Surgery, Pediatrics, and Dermatology and Venereology. Data were collected using a checklist including the common diseases within the scope of the study and each expert was asked to give percentages for children seen with each disease entity in his/her branch. Data analysis: Data were statistically analyzed using Statistical Package for the Social Sciences version 19. For each disease, the number and percentage were calculated and differences between observation recorded by health care workers in University and Ministry of Health were tested by chi-square test. P values $<0.05$ were considered significant.
\end{abstract}

Results: The most common 5 lesions in Middle Nile Delta region were herpes infection $(70.1 \%)$, candidiasis $(69.2 \%)$, aphthous ulcer $(67.3 \%)$, geographic tongue $(56.1 \%)$, and acute dental abscess $(49.7 \%)$. According to each branch; in Pedodontics; acute dental abscess $(95.5 \%)$, pulp polyp (94.5\%), parulis $(88.6 \%)$, herpes infection $(82.7 \%)$, and acute pericoronitis $(82.3 \%)$ were recorded. In Oral Medicine and Periodontology; herpes infection (95.5\%) was on the top, followed by physiologic pigmentation $(83.5 \%)$, candidiasis $(76.8 \%)$, aphthous ulcer $(75.0 \%)$, and geographic tongue $(70.5 \%)$, while in Oral and Maxillofacial Surgery; acute dental abscess $(68.1 \%)$, acute pericoronitis (59.2\%), odontoma (55.0\%), eruption cyst (49.2\%), and hemangioma $(46.7 \%)$ were recorded. In the Pediatric branch; the top lesion was candidiasis $(96.2 \%)$, followed

\footnotetext{
*Associate Professor of Pediatric Dentistry, Faculty of Dentistry, Kafrelsheikh University

**Associate Professor of Oral Medicine and Periodontology, Faculty of Dentistry, Kafrelsheikh University

***Associate Professor of Oral and Maxillofacial Surgery, Faculty of Dentistry, Tanta University

****Professor of Public Health and Community Medicine, Faculty of Medicine, Tanta University
} 
by the geographic tongue (79.2\%), herpes infection (74.2\%), aphthous ulcer $(68.7 \%)$, and scarlet fever (35.0\%). In Dermatology and Venereology; candidiasis $(87.0 \%)$, herpes infection $(74.5 \%)$, geographic tongue $(72.1 \%)$, physiologic pigmentation (70.0\%), and chickenpox (66.7\%) were the top 5 lesions.

Conclusion: In Middle Nile Delta, Egypt; the most common 5 pediatric oral lesions were herpes infection, followed by candidiasis, aphthous ulcer, geographic tongue, and acute dental abscess. The most common 5 lesions in each department; the results of Oral Medicine and Periodontology, Dermatology and Venereology, and Pediatrics were nearly similar but differ in the ranking, however, the Pedodontics and Oral \&Maxillofacial Surgery reported different lesions from the others but similar to each in 2 lesions.

KEYWORDS: oral lesions, children, prevalence, Middle Nile Delta, Egypt

\section{INTRODUCTION}

Pediatric oral lesions (POLs) have a lot of varieties, with clinical features, behavior, symptomatology, and prevalence differing from adults and youths ${ }^{(1)}$, and for some conditions, the prevalence increases with age. These lesions may be a normal/developmental finding, indicative of local or systemic infections, gingival and/or periodontal diseases, benign neoplasm or lifethreatening systemic diseases ${ }^{(2)}$. Moreover, POLs can be present as macules, ulcers, vesicles, changes in color, size alterations, and configuration of the oral anatomy ${ }^{(3)}$.

The exact prevalence of POLs is not well known. Although reports confirm the supporting of World Health Organization WHO recommendations to the epidemiological studies, few researches have been carried out on POLs so far ${ }^{(4,5)}$. On the other hand, almost published articles focused on a specific type of oral lesions ${ }^{(4,6-11)}$.

There is a considerable variation in lesions' prevalence among different regions of the world due to environment specificities, racial and lifestyle of each population. The study of the common POLs is important for the characterization of these lesions that are useful for early diagnosis and appropriate treatment ${ }^{(1)}$. Children with chronic diseases had a higher frequency of oral lesions compared to healthy ones.
The few studies that reviewed all types of oral lesions have many problems with ensuring the oral lesion standardization. Majorana et al. (12) recorded the most common lesions such as thrush, geographic tongue, traumatic ulcers, recurrent aphthous ulcer (RAU), herpes simplex virus (HSV) type 1, and erythema multiforme. On the other hand, Unur et al. (13) showed another arrangement; as fissured tongue followed by traumatic lesions, cheek biting, RAU, dento-alveolar abscess, cleft/ palate lip, recurrent herpes, Fordyce's granules, and thrush.

As for the benign lesions, the cystic and inflammatory lesions are more common than tumor or tumor-like lesions. Dentigerous cyst is more prevalent than other cystic lesions and the mucocele is the most frequent inflammatory lesions ${ }^{(4,11,13,14)}$. Among tumors, odontogenic tumors are the most common in this age, including odontoma on the top ${ }^{(5,14)}$.

Children with low socioeconomic background have high angular cheilitis and HSV, while RAU and geographic tongue are prevalent among children with a high level of socioeconomic status ${ }^{(15)}$.

Although the large variety of oral lesions and some certain lesions occur more in this age group ${ }^{(12)}$ and their prevalence is scarce and varies throughout the world ${ }^{(14)}$, there have been inadequate data about the prevalence of most common POLs in Egypt. Therefore, there is an increasing need for prevalence studies on this topic ${ }^{(16)}$. The aim of this study was 
to determine the most common 5 POLs referred to 5 branches related to children in both dentistry and medicine in Middle Nile Delta, Egypt.

\section{MATERIALS AND METHODS}

A qualitative study design was used depending on expert opinions to identify the burden of different oral lesions among children 0-14 years of age at different dental and medical departments. The target population of the study was experts in the following branches:

\section{- Pedodontics}

- $\quad$ Oral Medicine and Periodontology

- Oral and Maxillofacial Surgery

- Pediatrics

- Dermatology and Venereology

\section{Inclusion criteria:}

- Staff members, dentists, and physicians at the hospitals of Universities and the Ministry of Health, and Specialized Medical Centers \& hospitals were included in this study.

- These facilities offer health care services whether primary or secondary care level in the Middle Nile Delta region.

- Middle Nile Delta governorates: Kafrelsheikh, Gharbia, Menophia, and Kaluobia were included in this study.

- Staff members, dentists, and physicians who had at least 5 years of experience had participated in this study.

- Those having postgraduate studies in their specialties were more preferred than those who didn't have.

A sample of 240 seniors from each branch was recruited. Checklists (table 1) were given to participants for recording the perception of the burden of oral lesions in children under the age of 14 who were referred to them in a time span of 12 months.
The checklist was classified into 8 headings; cystic and exophytic, developmental, infections, ulcerative, neoplastic, pigmented, reactive/ inflammatory, and gingival \& periodontal lesions. All relative frequencies (percentages) of the most common POLs diagnosed were recorded.

The data were collected from 1164 participants using checklists including different POLs within the scope of the study. Each expert was asked to give both relative percentages for patients seen with each disease entity in his/her branch during last year from total patients served.

\section{Statistical analysis:}

The collected data were organized, tabulated and statistically analyzed using Statistical Package for the Social Sciences (SPSS) version 19 created by IBM, Illinois, Chicago, USA. For each disease, the number and percentage were calculated, and differences between observation recorded by health care workers in Universities and the Ministry of Health \& Specialized Hospitals were tested by Chisquare test. The level of significance was adopted at $\mathrm{p}<0.05$.

\section{RESULTS}

This study was conducted on 1164 health care workers covering 52 different types of oral lesions in children aged 0-14 years at 5 dental and medical departments. These lesions were classified under 8 headings based on their nature. The overall results of the most common 5 POLs in the 5 branches in Middle Nile Delta were herpes simplex infection (70.1\%) followed by candidiasis (69.2\%), aphthous ulcer $(67.3 \%)$, geographic tongue $(56.1 \%)$, and acute dental abscess $(49.7 \%)$. (Table 2 )

According to the most common 5 POLs in each branch (Table 3): In Pedodontics, the most common 5 lesions were acute dental abscess (95.5\%), pulp polyp (94.5\%), parulis (88.6\%), herpes simplex infection $(82.7 \%)$ and acute pericoronitis $(82.3 \%)$. 
TABLE (1) The checklist for determination of the most common pediatric oral lesions

\begin{tabular}{|c|c|c|c|}
\hline \multicolumn{4}{|c|}{ Category of the lesions } \\
\hline Cystic \&Exophytic & Rank in the group & Neoplastic & Rank in the group \\
\hline - Pulp Polyp & & 1-Benign: & \\
\hline - Eruption cyst & & - Odontoma & \\
\hline - Pyogenic granuloma & & - Ameloblastic fibroma & \\
\hline - Giant cell granuloma & & - Fibrous dysplasia & \\
\hline - Mucocele & & - Odontogenic fibroma & \\
\hline - Ranula & & 2- Malignant: & \\
\hline - Dentigerous cyst & & \multicolumn{2}{|l|}{ Pigmented } \\
\hline - Alveolar crest cyst & & - Hemangioma & \\
\hline - Epulis & & - Physiologic Pigmentation & \\
\hline \multicolumn{2}{|l|}{ Developmental } & - Amalgam Tattoo/Graphite & \\
\hline - Geographic tongue & & - Melanotic Nevus & \\
\hline - Fissured tongue & & \multirow{2}{*}{\multicolumn{2}{|c|}{ Reactive/Inflammatory }} \\
\hline - Coated tongue & & & \\
\hline - Ankyloglossia & & - Linea Alba (White Line) & \\
\hline - Abnormal labial frenum & & - Frictional (Traumatic) Keratosis & \\
\hline - Cleft lip and palate & & \multicolumn{2}{|l|}{ Gingival and Periodontal } \\
\hline \multicolumn{2}{|l|}{ Infections } & \multicolumn{2}{|l|}{ I-Gingival Enlargement(GE): } \\
\hline \multicolumn{2}{|l|}{ A-Viral: } & \multicolumn{2}{|l|}{ 1- Inflammatory: } \\
\hline - Herpes simplex virus & & - Acute:(Pericoronitis): & \\
\hline - HIV infection & & - Chronic & \\
\hline - Mumps & & \multicolumn{2}{|l|}{ 2- Modified by systemic diseases } \\
\hline - Herpangina & & \multicolumn{2}{|l|}{ A-Endocrine: } \\
\hline - Chickenpox & & -Juvenile diabetes, & \\
\hline - Measles & & -Puberty-induced GE & \\
\hline \multirow[t]{3}{*}{ - Hand, foot, and mouth disease } & & \multicolumn{2}{|l|}{ B-Blood dyscrasias: } \\
\hline & & - Leukemia & \\
\hline & & - Neutropenia & \\
\hline \multicolumn{2}{|l|}{ B-Fungal: } & C-Nutritional & \\
\hline Candidiasis & & 3- Modified by drugs-induced GE & \\
\hline \multicolumn{2}{|l|}{ C-Bacterial: } & \multicolumn{2}{|l|}{ II- Periodontitis: } \\
\hline - Acute dental abscess & & 1- Localized aggressive periodontitis & \\
\hline - Parulis & & \multicolumn{2}{|c|}{ 2-Periodontitis associated with genetic disorder: } \\
\hline \multirow[t]{2}{*}{ - Scarlet fever } & & A- Down's syndrome & \\
\hline & & B- Papillion Lefevre syndrome & \\
\hline \multicolumn{4}{|l|}{ Ulcerative } \\
\hline \multicolumn{4}{|l|}{ 1- Aphthous Ulcer } \\
\hline \multicolumn{2}{|l|}{ 2- Traumatic Ulcers: } & & \\
\hline A-Mechanical & & & \\
\hline B-Chemical & & & \\
\hline C-Electrical & & & \\
\hline
\end{tabular}


As for as Oral Medicine and Periodontology branch is concerned, the most common 5 lesions were herpes simplex $(95.5 \%)$, physiologic pigmentation $(83.5 \%)$, candidiasis $(76.8 \%)$, aphthus ulcer $(75.0 \%)$, and geographic tongue $(70.5 \%)$.

On the other hand, the most common 5 lesions in Oral and Maxillofacial branch were acute dental abscess (68.1\%), acute pericoronitis (59.2\%), odontoma $(55.0 \%)$, eruption cyst $(49.2 \%)$, and hemangioma $(46.7 \%)$.

In Pediatrics, candidiasis recorded the most common (96.2\%), followed by the geographic tongue $(79.2 \%)$, herpes simplex infection $(74.2 \%)$, aphthous ulcer (68.7\%) and scarlet fever (35.0\%).

Candidiasis (87.0\%), herpes simplex infection (74.5\%), geographic tongue $(72.1 \%)$, physiologic pigmentation $(70.0 \%)$, and chickenpox $(66.7 \%)$ were the most common recorded lesions in Dermatology and Venereology branch.

TABLE (2): The most common 10 pediatric oral lesions in Middle Nile Delta, Egypt

\begin{tabular}{|l|c|c|}
\hline \multirow{2}{*}{ Pediatric oral lesions } & \multicolumn{2}{|c|}{ First rank } \\
\cline { 2 - 3 } & $\mathrm{n}$ & $\%$ \\
\hline 1. Herpes simplex infection & 816 & 70.1 \\
\hline 2. Candidiasis & 806 & 69.2 \\
\hline 3. Aphthous Ulcer & 783 & 67.3 \\
\hline 4.Geographic tongue & 653 & 56.1 \\
\hline 5. Acute dental abscess & 578 & 49.7 \\
\hline 6. Physiologic Pigmentation & 484 & 41.6 \\
\hline 7. Pulp Polyp & 439 & 37.7 \\
\hline 8. Acute inflammatory GE (Pericoronitis) & 404 & 34.7 \\
\hline 9. Linea Alba (White Line) & 391 & 33.6 \\
\hline 10.Puberty-induced GE & 301 & 25.9 \\
\hline
\end{tabular}

TABLE (3): The most common pediatric oral lesions in relation to each department

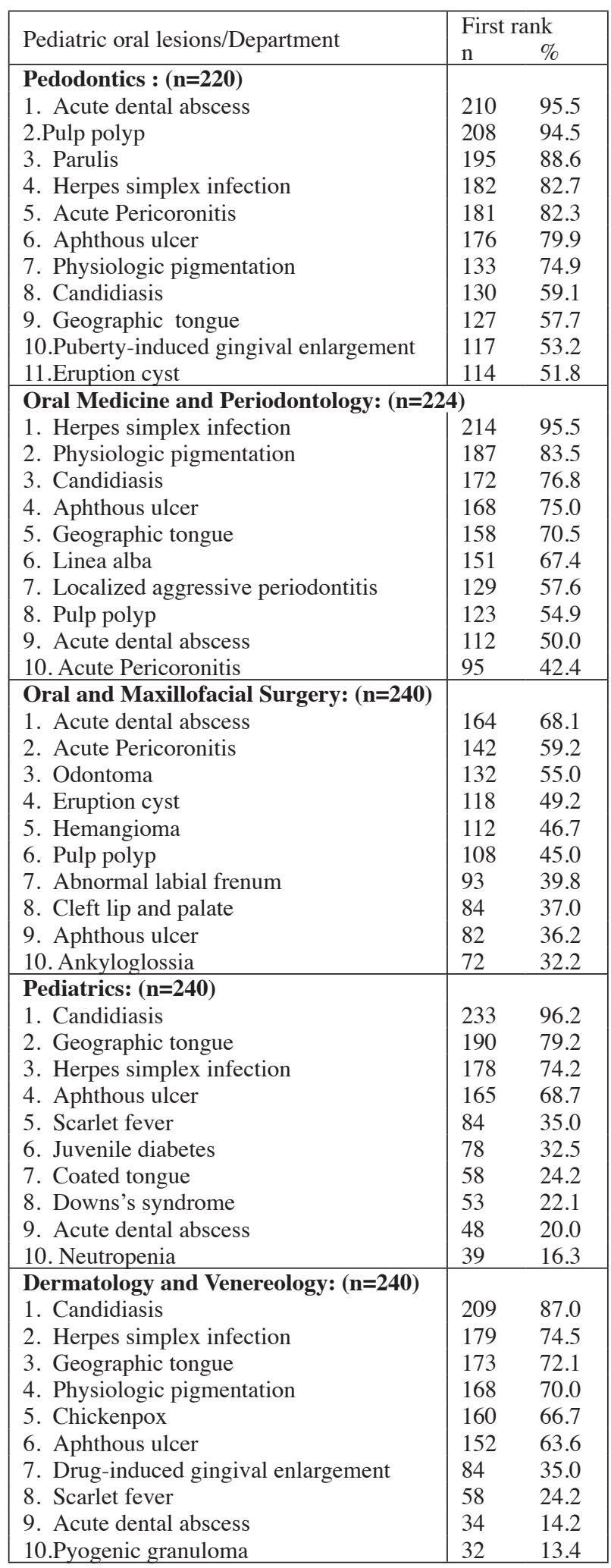


Table 4, concerning the cystic and exophytic category, the most common 5 POLs were pulp polyp (37.7\%), followed by eruption cyst (12.1\%), dentigerous cyst $(11.8 \%)$, mucocele $(4.7 \%)$, and ranula $(2.7 \%)$, while in the developmental category, the geographic tongue $(56.1 \%)$ was at the top, followed by abnormal labial frenum (13.8\%), coated tongue $(9.2 \%)$, ankyloglossia $(8.7 \%)$ and cleft lip and palate $(6.7 \%)$.
Herpes infection $(70.1 \%)$, candidiasis $(69.2 \%)$, acute dental abscess (49.7\%), scarlet fever (17.9\%), and parulis (16.9\%) were the most common 5 POLs in the category of infections.

It was found that among the ulcerative lesions, the aphthous ulcer was reported by $(67.3 \%)$ of participants as the most common lesion followed by the mechanical (11.0\%) and chemical ulcers (2.8\%).

TABLE (4): Distribution of pediatric oral lesions prevalence as perceived by studied dental and medical health care workers (Continued)

\begin{tabular}{|c|c|c|c|c|c|c|c|c|c|c|c|c|c|}
\hline \multirow{3}{*}{$\begin{array}{c}\text { Category of pediatric oral } \\
\text { lesions }\end{array}$} & \multicolumn{4}{|c|}{ University Hospitals } & \multicolumn{4}{|c|}{$\begin{array}{l}\text { Public and Specialized Hospitals } \\
\& \text { Centers of Ministry of Health }\end{array}$} & \multicolumn{4}{|c|}{ Total } & \multirow{3}{*}{$\mathrm{p}$} \\
\hline & \multicolumn{2}{|c|}{ Absent } & \multicolumn{2}{|c|}{ First rank } & \multicolumn{2}{|c|}{ Absent } & \multicolumn{2}{|c|}{ First rank } & \multicolumn{2}{|c|}{ Absent } & \multicolumn{2}{|c|}{ First rank } & \\
\hline & $\mathrm{n}$ & $\%$ & $\mathrm{n}$ & $\%$ & $\mathrm{n}$ & $\%$ & $\mathrm{n}$ & $\%$ & $\mathrm{n}$ & $\%$ & $\mathrm{n}$ & $\%$ & \\
\hline \multicolumn{14}{|l|}{ Infections: } \\
\hline Herpes simplex virus & 98 & 24.5 & 248 & 62.0 & 136 & 17.8 & 568 & 74.3 & 234 & 20.1 & 816 & 70.1 & 0.001 \\
\hline Candidiasis & 133 & 33.3 & 252 & 63.0 & 201 & 26.3 & 554 & 72.5 & 334 & 28.7 & 806 & 69.2 & 0.001 \\
\hline Acute dental abscess & 219 & 54.8 & 166 & 41.5 & 297 & 38.9 & 412 & 53.9 & 516 & 44.3 & 578 & 49.7 & 0.001 \\
\hline Scarlet fever & 276 & 69.0 & 83 & 20.8 & 599 & 78.4 & 125 & 16.4 & 875 & 75.2 & 208 & 17.9 & 0.001 \\
\hline Parulis & 284 & 71.0 & 74 & 18.5 & 448 & 58.6 & 123 & 16.1 & 732 & 62.9 & 197 & 16.9 & 0.001 \\
\hline Mumps & 286 & 71.5 & 24 & 6.0 & 509 & 66.6 & 34 & 4.5 & 795 & 68.3 & 58 & 5.0 & 0.018 \\
\hline Hand, foot, and mouth disease & 231 & 57.8 & 30 & 7.5 & 542 & 70.9 & 24 & 3.1 & 773 & 66.4 & 54 & 4.6 & 0.001 \\
\hline Herpangina & 313 & 78.3 & 14 & 3.5 & 563 & 73.7 & 16 & 2.1 & 876 & 75.3 & 30 & 2.6 & 0.003 \\
\hline Chickenpox & 286 & 71.5 & 6 & 1.5 & 548 & 71.7 & 15 & 2.0 & 834 & 71.6 & 21 & 1.8 & 0.042 \\
\hline HIV infection & 382 & 95.5 & 0.0 & 0.0 & 737 & 96.5 & 0.0 & 0.0 & 1119 & 96.1 & 0.0 & 0.0 & 1.000 \\
\hline Measles & 363 & 90.8 & 0.0 & 0.0 & 660 & 86.4 & 3 & 0.4 & 1023 & 87.9 & 3 & 0.3 & $0.195^{*}$ \\
\hline \multicolumn{14}{|l|}{ Ulcerative: } \\
\hline Aphthous ulcer & 102 & 25.5 & 291 & 72.8 & 231 & 30.2 & 492 & 64.4 & 333 & 28.6 & 783 & 67.3 & 0.001 \\
\hline Mechanical ulcer & 277 & 69.3 & 33 & 8.3 & 395 & 51.7 & 95 & 12.4 & 672 & 57.7 & 128 & 11.0 & 0.001 \\
\hline Chemical ulcer & 360 & 90.0 & 19 & 4.8 & 696 & 91.1 & 14 & 1.8 & 1056 & 90.7 & 33 & 2.8 & 0.021 \\
\hline Electrical ulcer & 397 & 99.3 & 0 & 0.0 & 747 & 97.8 & 9 & 1.2 & 1144 & 98.3 & 9 & 0.8 & 0.002 \\
\hline \multicolumn{14}{|c|}{ Neoplastic (Benign and malignant): } \\
\hline Odontoma & 288 & 72.0 & 83 & 20.8 & 541 & 70.8 & 154 & 20.2 & 829 & 71.2 & 237 & 20.4 & $0.588^{*}$ \\
\hline Fibrous dysplasia & 290 & 72.5 & 36 & 9.0 & 552 & 72.3 & 113 & 14.8 & 842 & 72.3 & 149 & 12.8 & 0.001 \\
\hline Odontogenic fibroma & 376 & 94.0 & 14 & 3.5 & 699 & 91.5 & 15 & 2.0 & 1075 & 92.4 & 29 & 2.5 & 0.002 \\
\hline Ameloblastic fibroma & 370 & 92.5 & 16 & 4.0 & 701 & 91.8 & 3 & 0.4 & 1071 & 92.0 & 19 & 1.6 & 0.001 \\
\hline Malignant neoplasm & 400 & 100 & 0 & 0.0 & 744 & 97.4 & 6 & 0.8 & 1144 & 98.3 & 6 & 0.5 & 0.015 \\
\hline
\end{tabular}

\section{* Not significant}


In the neoplastic category, odontoma (20.4\%) was the most common lesion, followed by fibrous dysplasia (12.8\%), odontogenic fibroma (2.5\%), and ameloblastic fibroma (1.6\%).

Regarding the pigmented lesions, the physiologic pigmentation (41.6\%) and hemangioma (15.5\%) were the most common recorded lesions. Among reactive/inflammatory lesion, participants revealed that linea alba was the most common as reported by (33.6\%).

As for the gingival and periodontal category, participants' response demonstrated that the acute pericoronitis $(34.7 \%)$, puberty-induced gingival enlargement (25.9\%), Juvenile diabetes $(21.0 \%)$, Down's syndrome (19.8\%), and drug-induced gingival enlargement (16.3\%) were the most common lesions.

The reported frequency of occurrence for each disease showed a statistically significant difference in relation to the type of hospital. However, this difference did not affect the overall ranking of the disease.

TABLE (4): Distribution of pediatric oral lesions prevalence as perceived by studied dental and medical health care workers (Continued)

\begin{tabular}{|c|c|c|c|c|c|c|c|c|c|c|c|c|c|}
\hline \multirow[t]{3}{*}{$\begin{array}{c}\text { Category of the pediatric oral } \\
\text { lesions }\end{array}$} & \multicolumn{4}{|c|}{ University Hospitals } & \multicolumn{4}{|c|}{$\begin{array}{c}\text { Public and Specialized } \\
\text { Hospitals \& Centers of Ministry } \\
\text { of Health }\end{array}$} & \multicolumn{4}{|c|}{ Total } & \multirow{3}{*}{$\mathrm{p}$} \\
\hline & \multicolumn{2}{|c|}{ Absent } & \multicolumn{2}{|c|}{ First rank } & \multicolumn{2}{|c|}{ Absent } & \multicolumn{2}{|c|}{ First rank } & \multicolumn{2}{|c|}{ Absent } & \multicolumn{2}{|c|}{ First rank } & \\
\hline & $\mathrm{n}$ & $\%$ & $\mathrm{n}$ & $\%$ & $\mathrm{n}$ & $\%$ & $\mathrm{n}$ & $\%$ & $\mathrm{n}$ & $\%$ & $\mathrm{n}$ & $\%$ & \\
\hline $\begin{array}{c}\text { Pigmented: } \\
\text { Physiologic pigmentation }\end{array}$ & 232 & 58.0 & 141 & 35.3 & 344 & 45.0 & 343 & 44.9 & 276 & 49.5 & 484 & 41.6 & 0.001 \\
\hline Hemangioma & 279 & 69.8 & 73 & 18.3 & 462 & 60.5 & 108 & 14.1 & 741 & 63.7 & 181 & 15.5 & 0.001 \\
\hline Melanotic nevus & 370 & 92.5 & 9 & 2.3 & 669 & 87.6 & 25 & 3.3 & 1039 & 89.3 & 34 & 2.9 & 0.002 \\
\hline Amalgam tattoo/graphite & 394 & 98.5 & 0 & 0.0 & 736 & 96.3 & 8 & 1.0 & 1130 & 97.1 & 8 & 0.7 & $0.204^{*}$ \\
\hline \multicolumn{14}{|l|}{ Reactive inflammatory: } \\
\hline Linea alba (White Line) & 270 & 67.5 & 119 & 29.8 & 460 & 60.2 & 272 & 35.6 & 730 & 62.7 & 391 & 33.6 & 0.040 \\
\hline Frictional keratosis & 342 & 85.5 & 26 & 6.5 & 577 & 75.5 & 38 & 5.0 & 919 & 79.0 & 64 & 5.5 & 0.001 \\
\hline $\begin{array}{l}\text { Gingival and periodontal: } \\
\text { Acute (pericoronitis) }\end{array}$ & 231 & 57.8 & 130 & 32.5 & 401 & 52.5 & 274 & 35.9 & 632 & 54.3 & 404 & 34.7 & $0.237 *$ \\
\hline Puberty-induced G. E & 305 & 76.3 & 86 & 21.5 & 485 & 63.5 & 215 & 28.1 & 790 & 67.9 & 301 & 25.9 & 0.001 \\
\hline Juvenile diabetes & 304 & 76.0 & 54 & 13.5 & 514 & 67.3 & 190 & 24.9 & 818 & 70.3 & 244 & 21.0 & 0.001 \\
\hline Down's syndrome. & 294 & 73.5 & 104 & 26.0 & 607 & 79.5 & 127 & 16.6 & 901 & 77.4 & 231 & 19.8 & 0.001 \\
\hline Drug induced G.E & 353 & 88.3 & 47 & 11.8 & 613 & 80.2 & 143 & 18.7 & 966 & 83.0 & 190 & 16.3 & 0.001 \\
\hline Chronic inflammatory G. E. & 366 & 91.5 & 33 & 8.3 & 634 & 83.0 & 130 & 17.0 & 1000 & 85.9 & 163 & 14.0 & 0.001 \\
\hline Localized aggressive perio & 317 & 78.8 & 47 & 11.8 & 537 & 70.3 & 103 & 13.5 & 852 & 73.2 & 150 & 12.9 & 0.003 \\
\hline Leukemia & 361 & 90.3 & 29 & 7.2 & 697 & 91.2 & 55 & 7.2 & 1058 & 90.9 & 84 & 7.2 & $0.604 *$ \\
\hline Neutropenia & 375 & 93.8 & 23 & 5.8 & 722 & 94.5 & 33 & 4.3 & 1097 & 94.2 & 56 & 4.8 & $0.316^{*}$ \\
\hline Papillion Lefevre syndrome & 358 & 89.7 & 27 & 6.8 & 648 & 84.8 & 21 & 2.7 & 1006 & 86.5 & 48 & 4.1 & 0.001 \\
\hline Nutritional disorder & 396 & 99.0 & 4 & 1.0 & 756 & 99.0 & 8 & 1.0 & 1152 & 99.0 & 12 & 1.0 & $1.000^{*}$ \\
\hline
\end{tabular}

* Not significant 


\section{DISCUSSION}

Over the past few years, the prevalence of oral mucous lesions has shown considerable variation among different regions throughout the world and has led researchers to draw disparate conclusions. Furthermore, studies have not been designed using standard protocols and criteria, further explaining the wide variation in methodology and the percentage of different groups of POLs ${ }^{(5)}$.

Moreover, in the literature, the prevalence of the most common POLs in Egypt is scarce and is absent in the Nile Delta, Egypt. Therefore, this prevalence study tries to determine the most common 5 POLs in the Middle Nile Delta referred to 5 dental and medical branches.

One of the important parameters for assessing the population's oral health is the prevalence of oral lesions whose data is a guideline for outlining oral health care services. Data collection from patients' files is usually subject to restrictions such as inadequate information which is not designed for research and missing important data. Also, another restriction is the poor quality of record keeping, leading to lost files. For these reasons, the authors in this study used a qualitative study design that depending on expert opinions by using checklists.

The checklist is a helpful method for data collection and its advantages include promoting objectivity, preventing memory lapses, improving organization and affordability. However, its disadvantages can't be ignored. It doesn't allow explanations and time-consuming ${ }^{(17)}$.

Determination of the top POLs would prompt implementation of appropriate policy towards improving awareness, diagnosis and proper management and planning oral health care services for these lesions ${ }^{(18)}$. Furthermore, the prevalence of these lesions is important for the specificity of their most common clinical characteristics in children frequently treated the same way as in adults, and the tendency of disease incidence in pediatric patients ${ }^{(19)}$. This agrees with Petersen et al. ${ }^{(20)}$ and Bhatnagar et al. (21) who stated that the prevalence of oral lesions is an important parameter for the evaluation of the oral health of any population. In addition, it is mandatory in specific population groups to understand their extension and characteristics, and to the improvement of oral health promotion and awareness programs for specific age groups, as recommended by WHO.

Moreover, caution should be used in applying reported prevalence unless the ages and other demographic characteristics of the subjects are similar to those of the patients in question ${ }^{(15)}$. Thus, the Middle Nile Delta region was selected.

Five dental and medical branches in this study were selected, as they had a close relationship to children, where some symptoms of their some diseases were manifested as pediatric oral lesions.

This study limited the prevalence of POLs to 0-14 years old, in the literature, the publication on oral lesions survey involve a variety of age ranges: $0-5$ years old ${ }^{(22)}, 0-12$ years old ${ }^{(12)}, 0-13$ years old ${ }^{(13)}, 3-13$ years old ${ }^{(3)}, 0-15$ years old ${ }^{(23)}, 0$-18 years old ${ }^{(24)}, 13-18$ years old ${ }^{(25)}$, and 0-20 years old ${ }^{(26)}$. In spite of the fact that all these age groups were considered in the pediatric range, we adopted the upper limit of 14 years because our intention was to emphasize the prevalence of POLs that were observed in a recent permanent dentition and an oral cavity development compatible with this dental age ${ }^{(19)}$. These age groups coincided with the age groups of Sousa et al. ${ }^{(19)}$ study.

Comparison with other prevalence results is not easy, due to the socio-demographic characteristics differences of the samples, local habits, dissimilar clinical diagnostic criteria, and the methodology used. These differences should be taken into consideration when comparing the frequency and distribution of oral mucosal lesions among children age groups ${ }^{(27)}$. 
In this study, the overall results of the most common 5 POLs recorded in Middle Nile Delta were HSV infection, followed by candidiasis, aphthous ulcer, geographic tongue, and acute dental abscess. This agrees with Rioboo-Crespo et al. (5) who reported that aphthous ulcer, HSV, geographic tongue, candidiasis, and traumatic lesions are the lesions that stand out when the results of published studies are examined. In addition, our results coincide with the results of Boras et al. ${ }^{(16)}$ who demonstrated that the majority of their Croatian children had HSV infection, aphthous ulcer, traumatic lesions, and geographic tongue.

Herpes and candidal infections are quite widespread in the pediatric age groups; however, their prevalence varies throughout the world. It seems that HSV infections are the most common ones in children. Primary herpetic gingivostomatitis is the acute condition that can be seen when first encounter with the herpes virus. It characterized by vesiculo-ulcerative lesions of oral and perioral tissues and usually seen between the ages of 6 months to 6 years. Recurrent herpes labialis and recurrent intraoral herpes are other types ${ }^{(13)}$.

In our study, HSV infection was at the top of the lesions, this can be attributed to the higher infection rate caused by the overcrowding of children in primary schools and the low socioeconomic status of the Middle Nile Delta region. This is confirmed by the studies of Ramos-Gomez ${ }^{(28)}$ and Boras et al. ${ }^{(16)}$ who reported that HSV infections are more prevalent in children from low socio-economic populations.

The results of the present study are in concordance with that reported by Amadori et al. ${ }^{(25)}$ who found that aphthous ulcers, traumatic ulcerations, HSV, geographic tongue, candidiasis were the most common 5 POLs in Italy, but disagrees with the findings of Shulman et al. ${ }^{(29)}$ and Majorana et al. ${ }^{(12)}$ who found that HSV infection was ranked fourth and seventh among the list of oral lesions, respectively.
These findings suggest that the prevalence of HSV infection is quite widespread in the Middle Nile Delta, Egypt.

The second most common POLs in our study was oral candidiasis. It is one of the most common opportunistic fungal infections. It is a mainly disease of children and among the top 5 pathogens causing nosocomial bloodstream infections, approximately $8 \%-10 \%{ }^{(30)}$. Pseudomembranous candidiasis is the common type. The lesions are soft, white, sometimes milk curd like plaque, when it is wiped off, leaves a painful and red surface. The atrophic type is characterized by painful, atrophic, erythematous mucosa. Small vesicles and erosions can be seen in severe cases ${ }^{(13)}$. It is usually associated with predisposing factors such as prolonged antibiotics and steroid therapy, local trauma, malnutrition, endocrine disorders, and immunosuppressant ${ }^{(31)}$.

Our result is confirmed by the study of Zaoutis et al. ${ }^{(32)}$, who stated that most children are at high risk for disseminated candidiasis due to the previous predisposing factors. Also, this finding is in accordance with the study of Yilmaz et al. ${ }^{(33)}$ and Majorana et al. ${ }^{(12)}$ who found that candidiasis was the most common lesion in their results, but not in accordance with Boras et al. ${ }^{(16)}$ and Ashkavandi et al. ${ }^{(34)}$ who did not record candidal infections. This can be explained by the recruitment of their data from the Department of Oral Medicine \& Periodontology and Oral \& Maxillofacial Surgery, respectively, compared to our study where the data were obtained from 5 dental and medical departments.

Aphthous ulcer was the third most frequent type of oral lesions in our results. It is one of the most common oral diseases, often seen in childhood and adolescence, and clinically has 3 forms; minor, major and herpetiform aphthous. The minor form is the most common type. It characterized by painful oral ulceration recurring with varying frequency (13). It categorized as an idiopathic disease as the exact etiology remains unclear. It is frequently 
misdiagnosed, treated incorrectly, or simply ignored ${ }^{(35)}$.

The finding of this study lent support to Majorana et al. ${ }^{(12)}$ who recorded oral candidiasis, traumatic lesions, recurrent aphthous, geographic tongue, and oral herpes. Many studies have shown that aphthous ulcer is one of the most common oral lesions in children ${ }^{(5,13,36-38)}$.

Geographic tongue is said to be one of the most prevalent oral conditions in the pediatric population; however, its prevalence varies widely across the studied populations ${ }^{(39)}$. It is an inflammatory disorder with unknown etiology. It is characterized by desquamation of filiform papillae in the dorsum and lateral border of the tongue circumfusing with the formation of red and round patches with white distinct borders that give the tongue a map-like appearance. It is usually painless but can cause burning sensations ${ }^{(13)}$.

In the present study, the geographic tongue is the fourth most common POLs. This finding is in agreement with Criveli et al. ${ }^{(40)}$, Bessa et al. ${ }^{(41)}$, and Majorana et al. ${ }^{(12)}$ who demonstrated that geographic tongue was one of the most common pediatric oral lesions in their findings. Similar results were found in the studies of Bánóczy et al. ${ }^{(42)}$, Uner et al. ${ }^{(13)}$, and Amadori et al. ${ }^{(25)}$ who reported a higher incidence of geographic tongue in young age.

Orofacial infections are a common health care concern in children and are a frequent cause of dental consultation worldwide ${ }^{(43)}$. Infection of dental origin is one of the most common diseases affecting the orofacial region ${ }^{(44)}$.

Acute dental abscess was the fifth most common POLs in our study. It is likely to be present among children with a high prevalence of trauma and dental caries ${ }^{(45)}$. This agrees with the study of Abbass et al. (46) and El Shazly \& Gabr ${ }^{(47)}$ who concluded that there is a higher incidence of dental caries among children in Egypt and in one of Middle Nile Delta
Governorates, respectively. This result may be attributed to the neglected dental caries and other health problem in underdeveloped or developing countries like Egypt, as the poor oral health is linked with the low level of socio-economic status, educational conditions and dietary habits ${ }^{(46,48)}$. The results of Uner et al ${ }^{(13)}$, Garcia Pola et al. ${ }^{(38)}$, and Arendorf \& van der Ross ${ }^{(49)}$ studies recorded high incidence of dentoalveolar abscesses which are similar to our findings, in contrast, the study of Benevides et al. ${ }^{(50)}$ reported very low incidence.

Finally, we have to admit that some of the similar studies didn't include periapical abscess in the oral lesions ${ }^{(5,13,39)}$ because these authors considered this lesion as tooth related lesion and not an oral mucosal lesion.

In this study, 3 of the 5 branches; Oral Medicine and Periodontology, Dermatology and Venereology, and Pediatrics showed nearly similar results but differed in lesions ranking, where 4 of the most common 5 POLs were similar in both Oral Medicine \& Periodontology and Dermatology \& Venereology, and in both Oral Medicine \& Periodontology and Pediatrics . However, the Pedodontics and Oral and Maxillofacial branches showed different results from the other branches but both branches included 2 similar lesions in their results. This can be explained by the specialties of Oral Medicine and Periodontology, Dermatology and Venereology, and Pediatrics have a close relation in some of their curricula. Furthermore, this could be attributed to the fact that most parents do not know the appropriate specialty to treat their diseased children as these lesions could be managed by any of the previous departments. However, the Pedodontic and Oral \& Maxillofacial branches were related to some extent but away from the other specialties, this may be due to the nature of their specialty.

As for the categories of lesions, the infection was the most common of them, including 3 lesions of the most common 5 POLs in Middle Nile Delta; two on 
the top and the other at the last rank representing by herpes infection, candida, and acute dental abscess, respectively. Aphthous ulcer was more prevalent in ulcerative lesion whereas geographic tongue was the most frequent developmental lesion and both lesions representing the third and fourth rank, respectively. This may be attributed to the presence of these lesions in the curricula of the 5 departments.

The physiologic pigmentation and pulp polyp were the most frequent pigmented and cystic \& exophytic lesions, respectively. As for the gingival and periodontal category, gingival lesions were more prevalent than periodontal, represented by acute pericoronitis and Puberty-induced gingival enlargement. This supported by the study of Pari et al. ${ }^{(51)}$ who reviewed that the gingival diseases are more common in children than periodontal. Whereas linea alba was the common inflammatory and reactive lesions. Among tumors, odontoma was found on the top of the benign but not from the top 10 lesions, this may be explained by the nature of the category that is mainly related to branch with more specialty such as oral surgery and pedodontics.

So, determination and identification of the burden of lesions and frequency of each one are important for policymakers. They are essential to have evidencebased data, helping better allocation of resources and, optimizing of currently available resources and minimizing of any waste. The data are also helpful for academia to focus on educational and training curricula on diseases commonly encountered by health care workers during their daily work, which will be reflected in providing high-quality services. It will also help to avoid teaching curricula jammed with unnecessary topics to students ${ }^{(1,20,21,46)}$.

For the majority of diseases, the distribution of diseases was statistically different in relation to the type of hospital whether related to the Ministry of Health or Universities. This difference did not affect much of the priority of the diseases rather than reflecting the severity of the diseases necessitating admission in more specialized hospitals as a university one.

Finally, this study suggests that further research should be conducted on studying more pediatric oral lesions in each pediatric age group, and on each branch. In addition, a larger population from different governorates may have allowed broader diversity for better representation for Egyptian pediatric population. Moreover, this study showed that there is an urgent need for upgrading the registration system in our hospitals.

\section{CONCLUSION}

- The prevalence of the most common 5 oral lesions in the Middle Nile Delta pediatric population under the age of 14 was: herpes infection, followed by candidiasis, aphthous ulcer, geographic tongue, and acute dental abscess,

- As regards the most common 5 pediatric oral lesions in each department :

- Three of the most common 5 lesions were similar but differ in the lesions ranking in both Oral Medicine \& Periodontology and Dermatology \& Venereology dept, and in both Oral Medicine \& Periodontology and Pediatrics dept.

- However, both Pedodontics and Oral \& Maxillofacial branches showed different lesions from the other branches, but they were similar to each other in 2 lesions.

\section{REFERENCES}

1. Vale EB, Ramos-Perez FM, Rodrigues GL, Carvalho EJ, Castro JF, Perez DE . A review of oral biopsies in children and adolescents: A clinicopathological study of a case series. J Clin Exp Dent 2013 1; 5:e144-149.

2. Keels MA. Soft tissue lesions of the oral cavity in children. Uptodate.com 2017.

3. Yanez M, Escobar E, Oviedo C, Stillfried A, Pennacchiotti G. Prevalence of oral mucosal lesions in children. Int J Odontostomat 2016; 10:463-468. 
4. Guerrisi M, Piloni MJ, Keszler A. Odontogenic tumors in children and adolescents A 15-year retrospective study in Argentina. Med Oral Patol Oral Cir Bucal 2007; 12:E180185.

5. Rioboo-Crespo Mdel R, Planells-del Pozo P, Rioboo-García R. Epidemiology of the most common oral mucosal diseases in children. Med Oral Patol Oral Cir Buccal 2005; 10:376-387.

6. Elarbi M, El-Gehani R, Subhashraj K, Orafi M. Orofacial tumors in Libyan children and adolescents A descriptive study of 213 cases. Int J Pediatr Otorhinolaryngol 2009; 73:237-242.

7. Bonder L. Cystic lesion of the jaws in children. Int J Pediatr Otorhinolaryngol 2002; 62:25-29.

8. Nico MM, Park JH, Lourenco SV. Mucocele in pediatrics: analysis of 36 children. Pediatr Dermatol 2008; 25:308311.

9. Gultelkin SE, Tokman B, Turkseven MR. A review of pediatric oral biopsies in Turkey. Int Dent J 2003; 53:26-32.

10. Torbs RB, Mader E, Friedrich T, Bennek J. Oral tumors and tumor-like lesion in infants and children. Pediatr Surg Int 2003; 19:639-645.

11. Espinosa-Zapata M, Loza-Hernandez G, Mondragon-Ballesteros B. Prevalence of buccal mucosa lesions in pediatra patients, prelimitary report. Cir Cir 2006; 74:153-157.

12. Majorana A, Bardellini E, Flocchini P, Amadori F, Conti $\mathrm{G}$, Campus G. Oral mucosal lesions in children from 0 to 12 years old: ten years' experience. Oral Surg Oral Med Oral Pathol Oral Radiol Endod 2010; 110:e13-e18.

13. Unur M, Kayhan KB, Altop MS, Metin ZB, Keskin Y. The prevalence of oral mucosal lesions in children: a single center study. J Istanb Univ Fac Dent 2015; 49: 29-38.

14. Sklavounou-Andrikopoulou A, Piperi E, Papanikolaou V, Karakoulakis I. Oral soft tissue lesions in Greek children and adolescents: a retrospective analysis over a 32-year period. J Clin Pediatr Dent 2005; 29:175-178

15. Dhanuthai K, Banrai M, Limpanaputtajak S. A retrospective study of pediatric oral lesions from Thailand. Int J Paediatr Dent 2007; 17:248-253.

16. Boras VV, Rogulj AA, Alajbeg I, Škrinjar I, Brzak BL, Brailo $\mathrm{V}$, et al. The prevalence of oral mucosal lesions in Croatian children. Paediatr Croat 2013; 57:235-238.
17. Pinsonneault A, Kraemer KL. Survey research methodology in management information systems: An assessment. JMIS 1993; 10:75-105.

18. Noubiap JJ, Essouma M, Bigna JJ, Jingi AM, Aminde LN, Nansseu JR. Prevalence of elevated blood pressure in children and adolescents in Africa: a systematic review and meta-analysis. Lancet Public Health 2017; 2:e375-e386.

19. Sousa FB, Correa L, Etges A, Mesquita RA. Pediatric oral lesions: a 15-year review from São Paulo, Brazil. J Clin Pediatr Dent 2002; 26:413-418.

20. Petersen PE, Estupian-Day S, Ndiaye C. WHO's action for continuous improvementin oral health. Bull World Health Organ 2005; 83:642.

21. Bhatnagar P, Rai S, Bhatnagar G, Kaur M, Goel S, Prabhat M. Prevalence study of oral mucosal lesions, mucosal variants, and treatment required for patients reporting to a dental school in North India: In accordance with WHO guidelines. J Family Community Med 2013; 20: 41-48.

22. Padovani MC, Santos MT, Sant' Anna GR, Guaré RO. Prevalence of oral manifestations in soft tissues during early childhood in Brazilian children. Braz Oral Res 2014; 28. pii: S1806-83242014000100246. Epub 2014 Aug 21.

23. Lei F, Chen J, Lin L, Wang W, Huang H, Chen C, Ho $\mathrm{K}$, Chen Y. Retrospective study of biopsied oral and maxillofacial lesions in pediatric patients from Southern Taiwan. J Dent Sci 2014; 9:351-358.

24. Maaita JK. Oral tumors in children: a review. Clin Pediatr Dent 2000; 24:133-135.

25. Amadori F, Bardellini E, Conti G, Majorana A. Oral mucosal lesions in teenagers: a cross-sectional study. Ital J Pediatr 2017; 43: 50.

26. Krishnan R, Ramesh M, Paul G. Retrospective Evaluation of Pediatric Oral Biopsies from A Dental and Maxillofacial Surgery Centre in Salem, Tamil Nadu, India. J Clin Diagn Res 2014; 8: 221-223.

27. Furlanetto DC, Crighton A, Topping GA. Differences in methodologies of measuring the prevalence of oral mucosal lesions in children and adolescents. Int J Ped Dent 2006; 16:31-39.

28. Ramos-Gomez F. Dental considerations for the pediatric AIDS/HIV patient. Oral Dis 2002;8:49-54.

29. Shulman JD. Prevalence of oral mucosal lesions in children and youths in the USA. Int J Ped Dent 2005; 15:89-97. 
30. Wisplinghoff H, Bischoff T, Tallent SM, Seifert H, Wenzel RP, Edmond MB. Nosocomial bloodstream infections in US hospitals: Analysis of 24,179 cases from a prospective nationwide surveillance study. Clin Infect Dis 2004; 39:309-317

31. Rodloff C, Koch D, Schaumann R. Epidemiology and antifungal resistance in invasive candidiasis. Eur J Med Res 2011;16:187-195.

32. Zaoutis TE, Greves HM, Lautenbach E, Bilker WB, Coffin SE. Risk factors for disseminated candidiasis in children with candidemia. Pediatr Infect Dis J 2004;23:635-641.

33. Yilmaz AE, Gorpelioglu C, Sarifakioglu E, Dogan DG, Bilici M, Celik N. Prevalence of oral mucosal lesions from birth to two years. Nig J Clin Prac 2011;14:349-353.

34. Ashkavandi ZF, Sheshdeh ZA, Kamali F. Orofacial Pathologic Lesions in Children and Adolescents: A Clinicopathological Study in Southern Iran. Iran J Pediatr 2014; 24 : 307-312.

35. Belenguer-Guallar I, Jiménez-Soriano Y, Claramunt-Lozano A. Treatment of recurrent aphthous stomatitis. A literature review. J Clin Exp Dent 2014; 6:e168-174.

36. Erthal A, Lourenço SV, Nico MS. Oral mucosal diseases in children - casuistics from the Department of Dermatology- University of São Paulo - Brazil. An Bras Dermatol 2016;91:849-851.

37. Gándara P, Somoza JM, García A, Gándara JM. Estomatitis aftosa recidivante. Diagnóstico y actualización terapéutica. Gaceta Dental 2002; 130:64-72.

38. Garcia-Pola MJ, Garcia-Martin JM, Gonzalez-Garcia M. Prevalence of oral lesions in the 6-year-old pediatric population of Oviedo (Spain). Med Oral 2002; 7:184-191.

39. Shah N, Kariya P, Dave B, Thomas P. Geographic Tongue: A Case Report with Review of Literature. Adv Hum Biol 2016: 6: 142-144

40. Crivelli MR, Aguas S, Quarrancino C, Bazerque P. Influence of the socioeconomic estatus on oral mucosa lesion prevalence in schoolchildren. Community Dent Oral Epidemiol 1988; 16:58-60.
41. Bessa CN, Santos PJ, Aguilar MF, Do Carmo MV. Prevalence of oral mucosal alterations in children from 0 to 12 years old. J Oral Pathol Med 2004; 33:17- 32.

42. Bánóczy J, Rigó O, Albrecht M. Prevalence study of tongue lesions in a Hungarian population. Community Dent Oral Epidemiol 1993 ; 21:224-226.

43. Nair RG, Salajegheh A, Itthagarun A, Pakneshan S, Brennan MT, Samaranayake LP. Orofacial viral infections - an update for clinicians. Dent Update 2014;41:518-520, 522-524.

44. Akinbami BO, Akadiri O, Gbujie DC. Spread of odontogenic infections in Port Harcourt, Nigeria. Oral Maxillofac Surg 2010;68:2472-2477.

45. Al-Malik M, Al-Sarheed M. Pattern of management of oro-facial infection in children: A retrospective. Saudi J Biol Sci 2017; 24: 1375-1379.

46. Abbass MS, Mahmoud SA, Rady D, AbuBakr N, Radwan, IA Ahmed A. The prevalence of dental caries among Egyptian children and adolescences and its association with age, socioeconomic status, dietary habits and other risk factors. A cross-sectional study. Version 1. F1000Res 2019; 8: 8 doi: 10.12688/f1000research.17047.1

47. El Shazly HM, Gabr HM. Prevalence and Risk Factors of Dental Caries among Preparatory School Children, Menoufia Governorate, Egypt. Asian J Med Health 2016; 1:1-11.

48. McGrady MG, Ellwood RP, Goodwin M, Boothman N, Pretty IA. Adolescents' perceptions of the aesthetic impact of dental fluorosis vs. other dental conditions in areas with and without water fluoridation. BMC Oral Health 2012;12:4.

49. Arendorf TM, van der Ross R. Oral soft tissue lesions in a black pre-school South African population. Community Dent Oral Epidemiol 1996; 24:296-297.

50. dos Santos PJ, Bessa CF, de Aguiar MC, do Carmo MA. Cross-sectional study of oral mucosal conditions among a central Amazonian Indian community, Brazil. J Oral Pathol Med 2004; 33:7-12.

51. Pari A, Ilango P, Subbareddy V, Katamreddy V, Parthasarthy H. Gingival Diseases in Childhood - A Review. J Clin Diagn Res 2014 ; 8: ZE01-ZE04. 